Adv Exp Med Biol - Advances in Internal Medicine (2018) 3: 407

https://doi.org/10.1007/5584_2018_204

(C) Springer International Publishing AG, part of Springer Nature 2018

Published online: 11 April 2018

\title{
Erratum to: Percutaneous Mitral Valve Interventions and Heart Failure
}

Abhishek Sharma, Sunny Goel, and Sahil Agrawal

\section{Erratum to:}

Chapter "Percutaneous Mitral Valve

Interventions and Heart Failure" in:

A. Sharma et al., Adv Exp Med Biol - Advances in Internal Medicine, https://doi.org/10.1007/5584_2017_142

In the original version of this chapter, the last name of the third author was incorrectly listed as Sahil Agarwal. It should actually read Sahil Agrawal and this has been corrected. 